\section{Role of Fetuin-A in Systemic Sclerosis-associated Calcinosis}

\section{To the Editor:}

Calcinosis, a soft-tissue calcification occurring in the setting of normal serum calcium and phosphate levels, has been observed in connective tissue diseases, including systemic sclerosis $(\mathrm{SSc})^{1}$, more frequently in the limited form (lcSSc) and in patients who are anticentromere antibody (ACA)-positive ${ }^{1}$. Calcinosis may be exceedingly painful and cause major clinical problems, including ulceration, infection, and joint contractures ${ }^{1}$. Hypovascularity, hypoxia, and tissue damage seem to favor its development, with genetic factors also playing a role. No treatment exists so far, and even surgical removal is unsatisfactory, since recurrences are common ${ }^{1}$.

Fetuin-A ( $\alpha$-2-Heremans-Schmid glycoprotein, AHSG) is a major inhibitor of systemic calcification, and low serum levels have been associated with vascular and soft-tissue calcifications ${ }^{2}$. Any situation that lowers serum fetuin-A, including inflammatory conditions, could increase the risk of calcification, because fetuin-A is a negative acute-phase protein. AHSG gene variations seem to influence fetuin-A serum concentration ${ }^{3}$.

Forty-one consecutive Italian patients with SSc [40 women, age $63 \pm$ 13 years, 16 diffuse SSc (dcSSc), 25 lcSSc] were studied. Standard hand, shoulder, pelvis, knee, and foot radiographs were reviewed by a radiologist blinded to the clinical data. All patients were screened for ACA (indirect immunofluorescence, Hep-2 cells) and topoisomerase I (ELISA); all had plasma levels of glucose, calcium, phosphorus, and C-reactive protein within normal limits; none had renal disease or cancer. Evaluation included disease duration, skin thickness, digital ulcers, visceral (lung, heart, gastrointestinal tract) and microvascular involvements, and treatment (immunosuppressants, calcium-channel blockers, prostanoids, endothelin receptor antagonists, proton pump inhibitors). Nailfold capillaroscopic analysis (videocapillaroscopy 200, DS Medica, Milan, Italy) was performed following the Sulli, et al indications ${ }^{4}$ using a semiquantitative scale from 0 to $3(0$, no changes; $1,<33 \%$ capillary alterations/reduction per linear $\mathrm{mm} ; 2,33 \%-66 \% ; 3,>66 \%$ ), and adding the scores to globally assess the microangiopathy ${ }^{4}$

Genotype analysis for the most common polymorphisms on the AHSG gene (T256S) was performed as described ${ }^{5}$. Due to technical problems, fetuin-A was measured (ELISA, Epitope Diagnostics Inc., San Diego, CA, USA) in only 23 randomly selected patients (13 lcSSc, $10 \mathrm{dcSSc}, 15$ calcinosis), and capillaroscopic analysis was done in 11 of these 23 .

Patients gave written informed consent. Approval was obtained by our Ethics Committee (ASL Milano 2, Italy; protocol number 2076).

Calcinosis was found in $48.8 \%$ of patients ( $13 \mathrm{lcSSc}, 7 \mathrm{dcSSc}$ ) and the hand was the most frequent site (65\% of patients, $7 \mathrm{lcSSc}, 6 \mathrm{dcSSc}$ ).

Fetuin-A levels were significantly lower in patients with calcinosis $(0.66 \pm 0.25$ vs $0.94 \pm 0.26 \mathrm{~g} / 1 ; \mathrm{p}=0.019)$, in patients with $1 \mathrm{cSSc}$, independently of calcinosis $(0.67 \pm 0.29 \mathrm{~g} / 1 \mathrm{in} \mathrm{lcSSc}$ vs $0.88 \pm 0.23 \mathrm{~g} / \mathrm{l}$ in $\mathrm{dcSSc} ; \mathrm{p}=0.065)$, and tended to be lower in ACA-positive patients $(0.71$ \pm 0.08 vs $0.82 \pm 0.09 \mathrm{~g} / \mathrm{l})$. No differences were found with respect to antitopoisomerase I autoantibodies. A significant relationship was found between fetuin-A, capillaroscopic abnormalities (Figure 1) and digital ulcers $(0.68 \pm 0.27 \mathrm{~g} / 1$ in patients with ulcers vs $0.91 \pm 0.26 \mathrm{~g} / 1$, patients with no ulcers; $p=0.07$ ). No relationships were found between fetuin-A, SSc duration, visceral involvement, skin thickness, or drugs (data not shown), nor between AHSG 256 C/G polymorphism, calcinosis (Table 1), and fetuin-A levels (data not shown).

To our knowledge, this is the first study to address the role of fetuin-A in SSc calcinosis. The high frequency of calcinosis we found is in agreement with the majority of reported data ${ }^{1}$.

The lower fetuin-A levels found in calcinosis would suggest its role as a calcification inhibitor also in SSc, and the lower levels found in patients with $\mathrm{lcSSc}$ are in accord with $\mathrm{lcSSc}$ as the type of SSc more frequently associated with calcinosis.

Few contrasting data exist concerning the relationship between fetuin-A levels and AHSG polymorphisms ${ }^{5,6}$, probably because of small

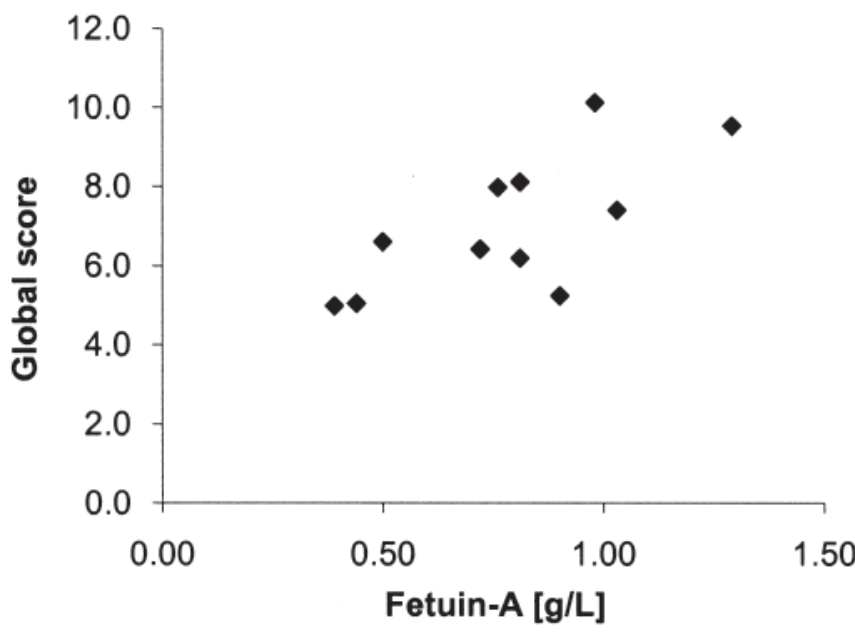

Figure 1. Relationship between fetuin-A serum levels and global capillaroscopic score in 11 patients with SSc. Global score was obtained from the sum of the scores of loss of capillaries, disorganization of the vascular array, giant capillaries, irregularly enlarged capillaries, capillary ramifications, and hemorrhages ${ }^{4}(r=0.72, p=0.01)$.

Table 1. AHSG $256 \mathrm{C} / \mathrm{G}$ gene polymorphism distribution in 41 patients with systemic sclerosis.

\begin{tabular}{lccl}
\hline AHSG 256 C/G & $\begin{array}{c}\text { Calcinosis }+, \\
\text { No. }(\%)\end{array}$ & $\begin{array}{c}\text { Calcinosis }-, \\
\text { No. (\%) }\end{array}$ & p \\
\hline CC & $1(5)$ & $3(14)$ & NS \\
GC & $5(25)$ & $5(24)$ & NS \\
GG & $14(70)$ & $13(62)$ & NS \\
G allele frequency & 0.82 & 0.74 & NS \\
\hline
\end{tabular}

AHSG: $\alpha$-2-Heremans-Schmid glycoprotein; NS: not significant.

sample sizes examined and different populations. In this respect, our study is in accord with the only other Italian report, which showed no association between AHSG polymorphisms and circulating fetuin- $\mathrm{A}^{5}$.

Our capillaroscopic data seem to indicate a role for fetuin-A in SSc microvascular damage, and are consistent with previous observations linking calcinosis to SSc vascular complications, and with the recent observation of a more prominent vascular disease in patients with $1 \mathrm{cSSc}{ }^{7}$. The observations that fetuin-A can contribute to endothelial dysfunction, has antifibrotic characteristics, and participates in tissue remodeling, coupled with the finding of an independent association between fetuin-A levels and endothelin-1 $(\text { ET- } 1)^{8}$, further support its role in SSc microangiopathy, since endothelial dysfunction, fibrosis, and ET-1 are involved in SSc pathogenesis9 .

Any association of fetuin-A with vascular disorders is under intense investigation, because of the potential for using fetuin-A as a treatment for calcifications. It worth noting that increasing fetuin-A with the phosphate binder sevelamer improved flow-mediated dilatation in chronic kidney diseases ${ }^{10}$.

Our data suggest a potential role for fetuin-A in microvascular involvement of SSc.

LAURA BELLOLI, MD; NICOLA UGHI, MD; MARCO MASSAROTTI, MD; BIANCA MARASINI, MD, Rheumatology Unit, IRCCS Istituto Clinico Humanitas, Università degli Studi; MARIA LUISA BIONDI, MD, Clinical Analysis Laboratory, San Paolo Hospital; GIORGIO BRAMBILLA, MD, Department of Radiological Imaging, IRCCS Istituto Clinico Humanitas, Milan, Italy. Address correspondence to Dr. L. Belloli, Via Manzoni 56, Rozzano 20089, Italy. E-mail: laurabelloli@tiscali.it 


\section{REFERENCES}

1. Boulman N, Slobodin G, Rozenbaum M, Rosner I. Calcinosis in rheumatic diseases. Semin Arthritis Rheum 2005;34:805-12.

2. Schäfer C, Heiss A, Schwarz A, Westenfeld R, Ketteler M, Floege $\mathrm{J}$, et al. The serum protein a2-Heremans-Schmid glycoprotein/ fetuin-A is a systemically acting inhibitor of ectopic calcification. J Clin Invest 2003;112:357-66.

3. Lebreton JP, Joisel F, Raoult JP, Lannuzel B, Rogez JP, Humbert G. Serum concentration of human alpha 2 HS glycoprotein during the inflammatory process: evidence that alpha $2 \mathrm{HS}$ glycoprotein is a negative acute-phase reactant. J Clin Invest 1979;64:1118-29.

4. Sulli A, Secchi ME, Pizzorni C, Cutolo M. Scoring the nailfold microvascular changes during the capillaroscopic analysis in systemic sclerosis patients. Ann Rheum Dis 2008;67:885-7.

5. Cozzolino M, Biondi ML, Galassi A, Gallieni M, d'Eril GV, Brancaccio D. Gene polymorphisms and serum alpha-2-H eremans-Schmid levels in Italian haemodialysis patients. Am J Nephrol 2007;27:639-42.
6. Fisher E, Stefan N, Saar K, Drogan D, Schulze MB, Fritsche A, et al. Association of AHSG gene polymorphisms with fetuin-A plasma levels and cardiovascular diseases in the EPIC-Potsdam study. Circ Cardiovasc Genet 2009;2:607-13.

7. Krieg T, Takehara K. Skin disease: a cardinal feature of systemic sclerosis. Rheumatology 2009;48 Suppl 3:iii14-8.

8. Wang XQ, Hayes MT, Kempf M, Fraser JF, Liu PY, Cuttle L, et al. Fetuin-A: a major fetal serum protein that promotes "wound closure" and scarless healing. J Invest Dermatol 2008;128:753-7.

9. Wigley FM. Vascular disease in scleroderma. Clin Rev Allergy Immunol 2009;36:150-75.

10. Caglar K, Yilmaz MI, Saglam M, Cakir E, Acikel C, Eyileten T, et al. Short-term treatment with sevelamer increases serum fetuin-A concentration and improves endothelial dysfunction in chronic kidney disease stage 4 patients. Clin J Am Soc Nephrol 2008;3:61-8.

J Rheumatol 2010;37:12; doi:10.3899/jrheum.100627 